\title{
Ci sono novità in tema di controllo del potassio?
}

\author{
Andrea Cavalli, Maria Carmen Luise, Giuseppe Pontoriero \\ S.C. Nefrologia e Dialisi, Ospedale "Alessandro Manzoni", Lecco
}

\begin{abstract}
Any news in potassium management?
Cardiovascular disorders are the leading cause of death in dialysis patients, with $27 \%$ of all deaths attributable to arrhythmic mechanisms that are at least partly due to variations in serum potassium levels. Recently, Karaboyas et al compared the two most common dialysate prescriptions ( $2 \mathrm{vs} 3 \mathrm{mEq} / \mathrm{L}$ ) in terms of the associated risk of death and arrhythmia. No meaningful differences were observed in mortality and arrhythmia outcomes. However, a serum potassium level higher than $5.6 \mathrm{mEq} / \mathrm{L}$ was associated with higher mortality and a higher arrhythmia risk. Moreover, there was a direct, albeit small, association with $+0.09 \mathrm{mEq} / \mathrm{L}$ serum potassium and every $+1 \mathrm{mEq} / \mathrm{L}$ dialysate potassium, suggesting the utility of strategies other than altering the dialysate potassium concentration in order to control potassium levels. Two new potassium-binding drugs are now under evaluation which hopefully will be found to have greater tolerability than the widely used sodium polystyrene sulfonate, which is associated with important gastrointestinal side effects. Patiromer was approved in the United States in 2015, while sodium zirconium cyclosilicate 9 could really be the most interesting molecule, considering its action in the higher gastrointestinal tract without any side effects. However, more studies are required, also in dialysis patients.
\end{abstract}

Keywords: Dialysate potassium, Hemodialysis, Hyperkalemia, Mortality, New potassium binders

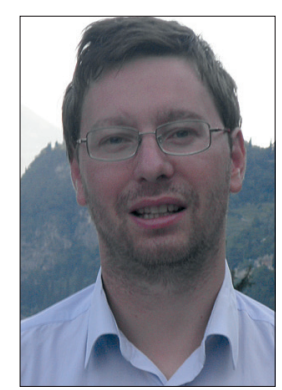

Andrea Cavalli
Sappiamo bene come la mortalità cardiovascolare sia elevata nei pazienti emodializzati, e in particolare il $27 \%$ di tutte le morti viene attribuito a meccanismi aritmici (1), che si concentrano poco prima della seduta post-intervallo lungo e nel periodo durante e immediatamente successivo alle sedute stesse (2), come conseguenza del significativo movimento di fluidi ed elettroliti.

È già stato anche evidenziato come elevati valori di potassio pre-dialitici rappresentino un fattore di rischio per morte improvvisa e mortalità per tutte le cause nei soggetti emodializzati (3). La concentrazione di potassio nel dialisato è un fattore - variabile - in grado di modificare i livelli ematici di potassio nel corso della seduta dialitica, che potrebbe anche aumentare il

Accepted: July 21, 2017

Published online: August 25, 2017

Indirizzo per la corrispondenza:

Dr. Giuseppe Pontoriero

S.C. Nefrologia e Dialisi

ASST Lecco, Ospedale "Alessandro Manzoni"

Via dell'Eremo, 9/11

23900 Lecco

g.pontoriero@asst-lecco.it rischio di aritmie, benché i dati attualmente disponibili siano discordanti in merito. Peraltro, non vi sono raccomandazioni ufficiali da parte della National Kidney Foundation-Kidney Disease Outcomes Quality Initiative (NKF-KDOQI) in merito alla "migliore" concentrazione di potassio nel bagno di dialisi, anche se pubblicazioni recenti sono concordi nel suggerire una scelta basata sui valori di potassiemia pre-dialitica di ogni paziente e nello scoraggiare concentrazioni inferiori a $2 \mathrm{mEq} / \mathrm{L}$ (specialmente in soggetti con elevate potassiemie pre-dialitiche) $(4,5)$.

Nel recentissimo articolo di Karaboyas et al (6) - condotto nell'ambito dello studio internazionale e prospettico DOPPS (Dialysis Outcomes and Practice Patterns Study), in corso ormai dal 1996 - sono state confrontate le due più comuni prescrizioni dialitiche di potassio ( 2 vs $3 \mathrm{mEq} / \mathrm{L}$ ), valutando i rischi di morte e aritmia a esse associate.

Sono stati considerati 55.183 pazienti nell'analisi primaria riguardante la mortalità per tutte le cause e 45.511 pazienti nell'analisi inerente l'outcome aritmico.

Analizzando le caratteristiche della popolazione studiata, i soggetti con potassiemia inferiore a $4 \mathrm{mEq} / \mathrm{L}$, rispetto a quelli con potassiemia superiore a $6 \mathrm{mEq} / \mathrm{L}$, erano più anziani, con un'età dialitica ridotta, maggiormente dializzati con un catetere venoso centrale, con minor apporto alimentare proteico e livelli minori di creatinina, albumina e fosforo. Le stesse caratteristiche si ritrovavano nei soggetti con più elevata concentrazione di potassio nel dialisato, oltre al fatto di avere potassiemie inferiori e maggior prescrizione di terapia diuretica (6). 